\title{
Characterization of Annona cherimola Mill. Seed Oil from Madeira Island: a Possible Biodiesel Feedstock
}

\author{
Pedro Costa Branco • Paula C. Castilho • \\ Maria Fernanda Rosa $\cdot$ Juan Ferreira
}

Received: 17 April 2009/Revised: 4 November 2009/Accepted: 6 November 2009/Published online: 28 November 2009 (C) AOCS 2009

\begin{abstract}
The possibility of using Annona seed oil as an added value product, namely as a source of biodiesel, is explored. Milled Annona seeds were extracted with hexane at room temperature $(72 \mathrm{~h})$ and at solvent boiling point (6 h). Oil content was found to be 25 and $22.4 \%$ respectively. The oil was characterized in terms of lipid composition (HPLC-APCI-MS and ${ }^{13} \mathrm{C}$ NMR), resistance to oxidation and acidity index. FAME composition was determined by GC-MS and five major peaks were identified. Production of biodiesel from Annona's seed oil was achieved by base-catalyzed transesterification. Density, viscosity, refraction coefficient, acid value, cold filter plugging point, cloud point and oxidation stability were measured. The iodine value and the "apparent cetane number" were calculated. Density, viscosity, acid value, iodine value, cold filter plugging point and cloud point were within EN14214 specifications and the calculated "apparent cetane number" was also indicative of a suitable product.
\end{abstract}

Keywords Annona seed oil · Residue valorization · Triacylglycerols · Fatty acid · Methyl ester .

Biodiesel production

P. C. Branco $(\varangle) \cdot$ P. C. Castilho $(\varangle)$ · J. Ferreira

Centro de Química da Madeira, Universidade da Madeira,

Campus Universitário da Penteada, 9000-390 Funchal, Portugal

e-mail: pcbranco@uma.pt

P. C. Castilho

e-mail: castilho@uma.pt

P. C. Branco - M. F. Rosa

Unidade de Biomassa, Departamento de Energias Renováveis,

Instituto Nacional de Engenharia, Tecnologia e Inovação,

Estrada do Paço do Lumiar 22, Edifício G,

1649-038 Lisbon, Portugal

\section{Introduction}

Residual agricultural products and food-processing by-products or wastes are often considered a problem. After processing, a large amount of plant material often remains without any application [1]. The conversion of such materials into valuable resources can be a good contribution to a reduction in residues. In this sense, residue valorization has become of great interest from an economical point of view.

Fruit seeds are often considered as waste products in some industries [2-4] and several studies have been carried out to evaluate their suitability as a source of biodiesel. This application can generate a great economical interest since industrial waste is then converted into a useful by-product. On the Madeira Island, Annona cherimola Mill. is consumed as fresh fruit and part of the production is exported. Yet, since this is a very sensitive fruit, approximately half of the total production is lost and 500 tons of waste are produced every year and this is usually disposed off or used as fertilizer. Seeds represent about $25 \%$ of the residue weight and may be used as a source of biodiesel. Seeds of other Annona species (Annona squamosa and Annona muricata) have been surveyed for their possible use as a source of biodiesel [5]. A. cherimola fruit production is largely developed in some Latin American countries, therefore large quantities of residue might be available.

Biodiesel (fatty acid alkyl esters) produced from vegetable oils has been considered a viable alternative to fossil diesel. As dedicated agro-production can have disastrous economical consequences there has been great discussion about using soils for energy crops instead of using them for feeding purposes. Therefore waste cooking oils and nonedible vegetable oils have been considered as a potential 
source of alternative fuels [3, 4], since they do not compete with food crops for the occupation of the soil. Waste seed oil can be considered as a non-edible vegetable oil, although in some African or Middle East countries pumpkin and melon seeds (waste products after the removal of the pulp and peel) are used to extract cooking oils [1].

Oil characterization is essential to evaluate its potential applications, such as cosmetics, nutrition [6] or fuel [7] industries. Chromatographic methods with mass spectrometric detection are well established to determine lipid composition. GC-MS is widely used to determine fatty acid (FA) composition, mainly as their methyl esters (FAMEs), and HPLC-MS has been used for triacyglycerol (TAG) characterization. ${ }^{13} \mathrm{C}$ NMR can also be used to quantify free fatty acids (FFA) and partial acylglycerols, which are normally present as traces [8].

Regarding fuel applications, the measurement of the oil's stability to oxidation and its acidity index can be screening methods to predict the suitability of the oil as a raw material for biodiesel production. Oils with low oxidation stability cannot be stored for a long time before conversion and it will probably result in a final product that most certainly is not itself resistant to oxidation processes. On the other hand, high FFA content (thus resulting in high acidity index) are inconvenient for basecatalyzed transesterification processes, since the catalyst is consumed in a saponification reaction and larger amounts of base are needed, lowering biodiesel yield as well as emulsifying the final product hindering glycerol separation [9].

\section{Methods}

Materials

Annona seeds were provided by AGRIPÉROLA-Cooperativa Agícola, C.R.L. (Funchal, Portugal). Hexane (95\%) and Acetonitrile (LC-MaScan) were purchased from LABSCAN Analytical Sciences (Dublin, Ireland), methanol (99.8\%), sodium chloride (analytical reagent), sodium hydroxide pellets (analytical reagent) and ethanol absolute (UV-IR-HPLC) from PANREAC (Barcelona, Spain), hydrochloric acid (37\%) and diethyl ether (99.5\%) from Riedel-de Haën (Seelze, Germany), propan-2-ol (HPLC Gradient grade) from Fisher Scientific (Loughborough, UK), hexane (for HPLC) from Acros Organics (NJ, USA), potassium hydroxide (analytical reagent) and anhydrous magnesium sulfate (analytical reagent) from Merck (Darmstadt, Germany), boron trifluoride methanol complex from BDH (Poole, England), glyceryl trilaurate $(\approx 99 \%)$, glyceryl tripalmitate $(\approx 99 \%)$ and glyceryl trioleate
(>99\%) from Sigma (Steinheim, Germany) and glyceryl tristearate ( $>99 \%)$ from Fluka (Steinheim, Germany).

\section{Oil Extraction and Characterization}

\section{Extraction Procedures}

Dry seeds were ground to a powder in an IKA ${ }^{\circledR}$ Werke (Staufen, Germany) MF10 basic mill. Powdered Annona seeds $(400 \mathrm{~g})$ were added to $4 \mathrm{~L}$ of hexane and stirred for $72 \mathrm{~h}$ at room temperature $\left(\approx 25^{\circ} \mathrm{C}\right)$. In parallel, an extraction at solvent boiling temperature $(6 \mathrm{~h})$ was carried out for comparison. Both hexane extracts were then filtered and evaporated in a rotary evaporator to eliminate solvent.

\section{Determination of the FFA Content by Titrimetry}

The acidity index of fresh oil was calculated according to ISO 660 standard method [10].

\section{Oil Resistance to Oxidation}

The FT-IR spectrum of the recently extracted oil was registered in a Mattson (Madison, WI, USA) Infinity Series FT-IR using $\mathrm{KBr}$ cells, accumulating 32 scans from 4,000 to $600 \mathrm{~cm}^{-1}$, with a scan resolution of $4 \mathrm{~cm}^{-1}$. Fresh oil $(10 \mathrm{~g})$ was placed in a covered Petri dish and kept at $70{ }^{\circ} \mathrm{C}$. FT-IR spectra were registered every $24 \mathrm{~h}$ as described before.

Induction period and stability curves were determined according to EN14112 [11] procedures in a Metrohm (Herisau, Switzerland) Rancimat ${ }^{\circledR}$ model 743 equipment.

\section{Determination of FA Composition}

FA were converted to FAME and determined according to the analytical methods described in regulations EEC/2568/ 91 [12] and EEC/1429/92 [13] of the European Union Commission for olive oil.

\section{FAME Analysis}

The FAME composition was determined by CG-MS [12, 13], using a Varian (Walnut Creek, CA, USA) Star 3400 Cx Series II gas chromatograph equipped with Varian (Walnut Creek, CA, USA) Saturn III mass selective detector and Saturn GC-MS workstation software. A J\&W (Rancho Cordova, CA, USA) DB-wax (30 m) column with $0.25 \mathrm{~mm}$ (i.d.) and $0.25 \mathrm{~mm}$ thickness coating film was used. Operating conditions: injector temperature, $240{ }^{\circ} \mathrm{C}$; initial temperature (column oven), $70^{\circ} \mathrm{C}$; heating ramp, $10{ }^{\circ} \mathrm{C} / \mathrm{min}$ to $180{ }^{\circ} \mathrm{C}, 10 \mathrm{~min}$ at $180{ }^{\circ} \mathrm{C}, 10^{\circ} \mathrm{C} / \mathrm{min}$ to $220{ }^{\circ} \mathrm{C}$ and $10 \mathrm{~min}$ at $220^{\circ} \mathrm{C}$. The ion trap detector was set 
as follows: transfer line temperature $220{ }^{\circ} \mathrm{C}$; manifold and trap temperatures $180{ }^{\circ} \mathrm{C}$; mass range $\mathrm{m} / z, 35-350$; emission current $15 \mathrm{~mA}$. The electron multiplier was set in the relative mode to the auto tune procedures. All mass spectra were acquired in the electron impact mode $\left(E_{\mathrm{i}}=70 \mathrm{eV}\right.$; source temperature, $\left.180{ }^{\circ} \mathrm{C}\right)$. The sample injection volume was $1 \mu \mathrm{L}$.

\section{Evaluation of the Lipidic Composition by ${ }^{13} C N M R$}

The oil, without any treatment, was dissolved in $\mathrm{CDCl}_{3}$ and analyzed by ${ }^{13} \mathrm{C}$ NMR. Spectra were recorded on a Bruker (Rheinstetten, Germany) AVANCE $400 \mathrm{II}+$ operating at $100.61 \mathrm{MHz}$, equipped with a 5-mm BBO probe. Chemical shifts $(\delta)$ are all relative to internal tetramethylsilane. The spectra were recorded at room temperature with a 2-s relaxation decay, a $45^{\circ}$ excitation pulse, a 2.36 -s acquisition time, a sweep total with of $24,038 \mathrm{~Hz}$ and $32-\mathrm{K}$ acquisition points to yield a digital resolution of $0.212 \mathrm{~Hz} /$ point [14].

\section{Determination of TAG Structure by HPLC-APCI-MS}

The TAG composition was determined using a Dionex (Germering, Germany) UltiMate 3000 series chromatograph equipped with a Phenomenex Gemini C18 column $(250 \times 3.0 \mathrm{~mm}, 5 \mu \mathrm{m}$ particle size) and a Bruker (Bremen, Germany) Esquire 6000 mass detector, using positivemode atmospheric pressure chemical ionization (APCI) with an ion-trap mass analyzer. The samples and column were kept at $30{ }^{\circ} \mathrm{C}$, and a gradient elution was effected by changing the mobile phase composition from acetonitrile/ ethanol (90:10) to $18 \%$ acetonitrile in $90 \mathrm{~min}$. The mobile phase flow was $0.7 \mathrm{~mL} / \mathrm{min} .3$ and $0.5 \%$ (w/v) solutions of the oil and standards (respectively) dissolved in acetonitrile/propan-2-ol/hexane (2:2:1) were prepared and $20 \mu \mathrm{L}$ was injected [15].

\section{Biodiesel Production and Characterization}

\section{Biodiesel Production Procedure}

Freshly obtained oil $(50 \mathrm{~mL})$ was heated to $60{ }^{\circ} \mathrm{C}$ in a round-bottom flask. Sodium hydroxide $(0.175 \mathrm{~g})$ was dissolved in $175 \mathrm{~mL}$ of methanol and added to the oil. The reaction was kept under reflux $\left(55-60^{\circ} \mathrm{C}\right)$ for $1 \mathrm{~h}$. The reaction mixture was then transferred to a separator funnel and left to cool down to room temperature. At this point two phases were observed. The biodiesel formed was washed with distilled water (15\% of biodiesel's volume) and the aqueous phase was discarded. The biodiesel was then washed with $0.5 \%$ aqueous $\mathrm{HCl}(5 \%$ of biodiesel's initial volume) and again with water (10\% of the initial volume of biodiesel) to remove soaps, the aqueous phases were discarded in both steps. Finally, the biodiesel obtained was dried with anhydrous magnesium sulfate, filtered and any excess water was evaporated in a rotary evaporator.

\section{Biodiesel Characteristics}

The following parameters were determined: density (picnometer method), kinematic viscosity (Ubbelohde capillary viscometer), iodine number (gas chromatography), acid value (titrimetry), cold filter plugging point (CFPP), cloud point, oxidation stability (Rancimat ${ }^{\circledR}$ method) and calculated "apparent cetane number" (Klopfenstein's equation).

Density was measured at $15{ }^{\circ} \mathrm{C}$ following the procedures indicated in UNE-EN 14214 [16] and kinematic viscosity was measured at $40{ }^{\circ} \mathrm{C}$, according to the EN ISO 3104 [17] standard method. The iodine number was obtained by gas chromatography, as laid out in UNE-EN 14214 [16]; GC-MS conditions were the same as described for FAME analysis. The procedure for calculating the acid value is the same as indicated for the oil's acidity index [10]. The CFPP was determined according to the EN 116 standard method [18] and the cloud point was determined by the ASTM D 2500 standard method [19]. The oxidation stability procedure was the same as previously described for the oil.

For each individual methyl ester "apparent cetane number" $\left(I_{\text {cetane,ME }}\right)$ can be estimated by using Klopfenstein's equation (Eq. 1) [20]. "Apparent cetane number" can then be predicted using Eq. 2 as the average of the product of each individual methyl ester contribution by its percentage in the mixture [21].

$I_{\text {cetane }, \mathrm{ME}}=58.1+2.8 \times \frac{(n-8)}{2}-15.9 \times \mathrm{DB}$

$I_{\text {cetane }}=\sum X_{\mathrm{ME}} \times I_{\text {cetane,ME }}$

where $n$ is the number of carbons in the acyl chain, DB the number of double bonds and $X_{\mathrm{ME}}$ the weight percentage of individual methyl ester.

\section{Results and Discussion}

The oil content of A. cherimola seeds was found to be $25.1 \%$ (in terms of neutral lipids), obtained by extraction with $n$-hexane at room temperature, while extraction at boiling temperature afforded only $22.4 \%$ of neutral lipids. These quantities are far below canola but above soybean oils, some usual sources of vegetable oil for biodiesel production [22]. 


\section{Oil Characterization}

The acidity number for the freshly extracted oil was $2.2 \mathrm{mg}$ $\mathrm{KOH} / \mathrm{g}$. This value is consistent with other raw vegetable oils suitable for biodiesel production. Yet this value should be reduced to values below $1.0 \mathrm{mg} \mathrm{KOH} / \mathrm{g}$ prior to alkali catalyzed transesterification. The most widely used method to reduce FFA content is the acid catalyzed pre-esterification [23].

The FT-IR spectrum of freshly obtained oil (Fig. 1a) shows a weak band at $3,474 \mathrm{~cm}^{-1}$, due to an overtone band of carbonyl group stretching [24]. The bands at 3,008, 1,653 and $917 \mathrm{~cm}^{-1}$, indicate the presence of cis unsaturated $\mathrm{FAs}$ and are due respectively to $\mathrm{C}-\mathrm{H}, \mathrm{C}=\mathrm{C}$ stretching and $\mathrm{C}=\mathrm{C}$ deformation (out-of-plane) in olefin groups $[25,26]$.

The high degree of unsaturation of $A$. cherimola seed oil makes it susceptible to oxidation. Although the traditional methods for establishing the oxidative state of oil and fats are chemical methods based on the measurement of the concentration of the main products generated in the process, such as peroxide value, anisidine value and iodine value, we present some observations based on infrared spectroscopy, since good correlations can be established between this and the traditional processes. FT-IR methods are increasingly being accepted for the evaluation and monitoring of oxidation processes in transformer and motor oils as well as vegetable oils, to replace costly, labor and time consuming chemical methods. These spectrometric methods combine speed of analysis, high sensitivity, precision and reproducibility, and require a minimum amount of sample [27-29].

The comparison of the IR spectra of the oil initially and after 8 and 12 days under oxidative conditions
(Fig. 1a, b and c) show some changes that indicate the oxidative process. At approximately $3,500 \mathrm{~cm}^{-1}$, an intense broad band appears after 8 days, indicating the presence of hydroperoxides. This band gets even more intense after 12 days. The disappearance, after 8 days, of the peak at approximately $3,000 \mathrm{~cm}^{-1}$ means that the double bonds are fully oxidized. The band corresponding to carbonyl stretching at $1,746 \mathrm{~cm}^{-1}$ has a drift to $1,743 \mathrm{~cm}^{-1}$ after 12 days. This indicates the formation of FFA, as oxidation product of triglycerides. Finally, the disappearance of the band at $1,119 \mathrm{~cm}^{-1}$ means that the degree of saturation rises, since the intensity of this band is inversely proportional to the degree of saturation [25, 26]. A new band is observed at $986 \mathrm{~cm}^{-1}$; this is absent from the spectrum of the freshly obtained oil and appears during the oxidation process. This band has been associated with bending vibrations of $\mathrm{CH}$ trans-trans-conjugated unsaturated FAs.

The standard test method to determine oxidation stability for biodiesel products is the Rancimat ${ }^{\circledR}$ method. The test was conducted for comparison with the previous results and the induction period for Annona seed oil was $3.96 \mathrm{~h}$.

These results indicate that the oil should not be kept stored for a long period, thus avoiding oxidation and consequently the increase of the FFA content, which will decrease the yield when converting the oil into biodiesel.

\section{FA Composition}

Five major peaks were found in the GC-MS chromatogram of FAME. The peaks were identified respectively as $\mathrm{C} 16: 0\left(\mathrm{RT}=22.36 \mathrm{~min} ; \mathrm{M}^{+}=270 \mathrm{~m} / \mathrm{z}\right), \mathrm{C} 18: 0(\mathrm{RT}=$
Fig. 1 FT-IR spectra of a freshly obtained oil and after b 8 days and c 12 days under oxidative conditions

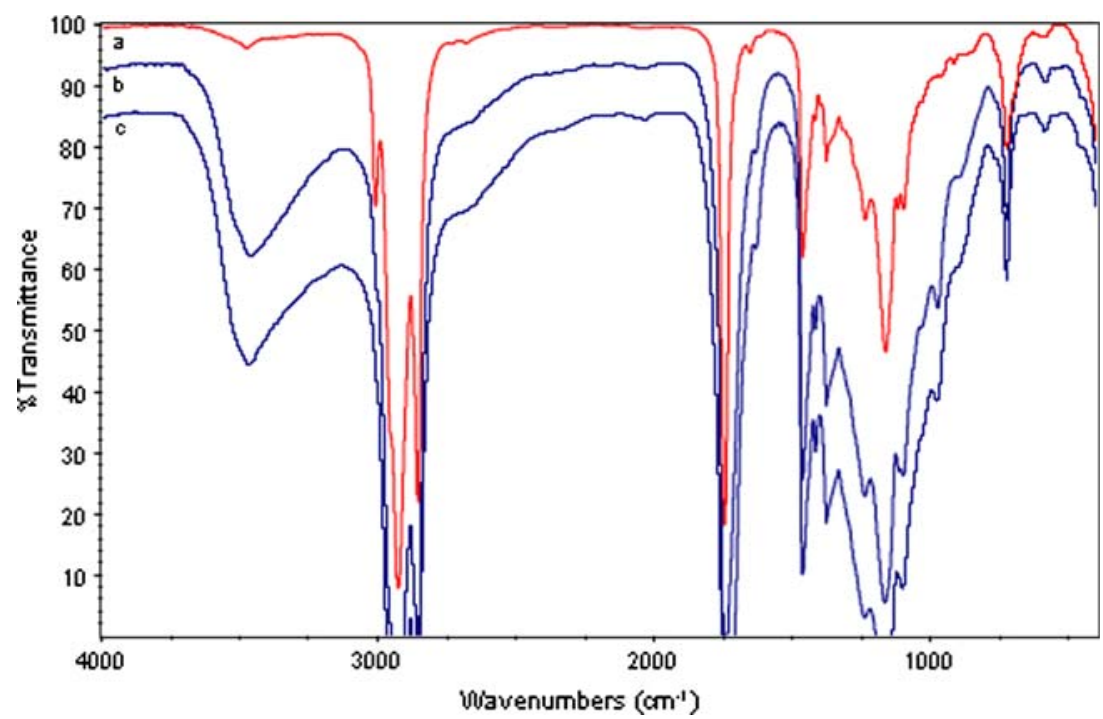


$\left.28.48 \mathrm{~min} ; \quad \mathrm{M}^{+}=298 \mathrm{~m} / \mathrm{z}\right), \quad \mathrm{C} 18: 1 \quad(\mathrm{RT}=29.21 \mathrm{~min}$; $\left.\mathrm{M}^{+}=296 \mathrm{~m} / \mathrm{z}\right), \mathrm{C} 18: 2\left(\mathrm{RT}=30.44 \mathrm{~min} ; \mathrm{M}^{+}=294 \mathrm{~m} / \mathrm{z}\right)$ and $\mathrm{C} 18: 3\left(\mathrm{RT}=32.19 \mathrm{~min} ; \mathrm{M}^{+}=292 \mathrm{~m} / \mathrm{z}\right)$, and their relative abundance is presented in Table 1 .

When compared with some leading sources [30] of biodiesel (Table 1) Annona seed oil has a higher content in palmitic acid, almost equal parts of oleic and linoleic acids (much different to soybean, rapeseed and sunflower oils [31]) and a low content in linolenic acid. This composition indicates that Annona seed oil is a potential biodiesel source and as stable to oxidation as soybean and sunflower oils.

\section{${ }^{13}$ C-NMR Analysis}

The spectrum of annona seed oil (Fig. 2) shows mainly the characteristic signals of TAG. 1,3-DAG signals are of very low intensity (so low that the signals of the glyceride carbons at ca. 65 ppm cannot be integrated) and 1,2-DAG (signals in the glyceride carbon region at ca. $72 \mathrm{ppm}$ ) and FFA (carbonyl resonance at ca. 176 ppm) are detectable as traces [8].

Although ${ }^{13} \mathrm{C}$ NMR can provide essential structural information about TAG, concerning the structure of the acyl groups and their distribution in the glycerol backbone, it was used in this study mainly to confirm that Annona seed oil contained essentially TAG.

\section{TAG Structure}

Eleven peaks, affording 17 TAG, were identified in the HPLC-APCI-MS chromatogram of the oil (Fig. 3). TAG elution in RP-HPLC is affected by both the combined number of carbon atoms in the acyl chain (ACN acyl carbon number) and the number of double bonds, $n$, in the molecule; as some critical groups (TAG with the same equivalent carbon number $\mathrm{ECN}=\mathrm{ACN}-2 n$ ) are usually difficult to separate [32], some peaks were a result of a co-eluted mixture of up to three TAG.

Table 1 FA composition of Annona seed oil and other vegetable oils used as biodiesel sources (\%)

\begin{tabular}{lrrrr}
\hline & $\begin{array}{l}\text { Annona } \\
\text { seed oil }\end{array}$ & $\begin{array}{l}\text { Soybean } \\
\text { oil }^{\mathrm{a}}\end{array}$ & $\begin{array}{l}\text { Rapeseed } \\
\text { oil }^{\mathrm{a}}\end{array}$ & $\begin{array}{l}\text { Sunflower } \\
\text { oil }^{\mathrm{a}}\end{array}$ \\
\hline Palmitic acid (C16:0) & 19.99 & 11.75 & 3.49 & 6.08 \\
Stearic acid (C18:0) & 4.16 & 3.15 & 0.85 & 3.26 \\
Oleic acid (C18:1) & 38.58 & 23.26 & 64.40 & 16.93 \\
Linoleic acid (C18:2) & 35.97 & 55.53 & 22.30 & 73.73 \\
Linolenic acid (C18:3) & 1.31 & 6.31 & 8.23 & 0.00 \\
\hline
\end{tabular}

${ }^{\mathrm{a}}$ Ma and Hanna [31]

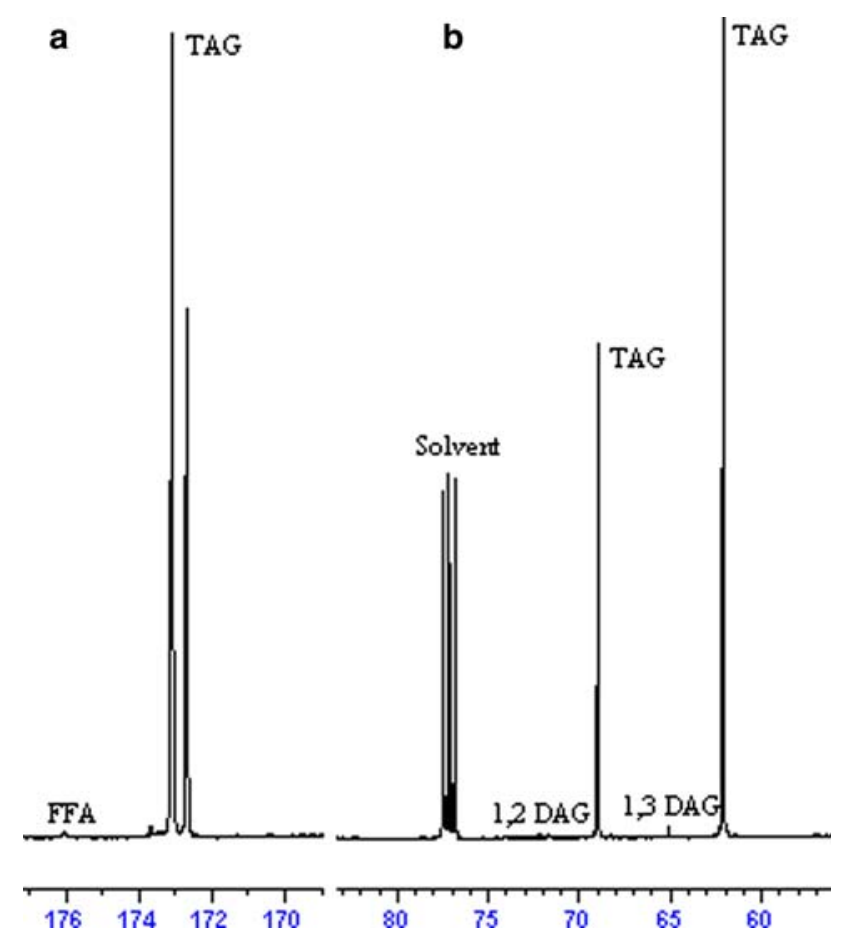

Fig. $2{ }^{13} \mathrm{C}-\mathrm{NMR}$ spectrum $(100.61 \mathrm{MHz})$ of a the carbonyl carbons and $\mathbf{b}$ the glycerol carbons of Annona seed oil

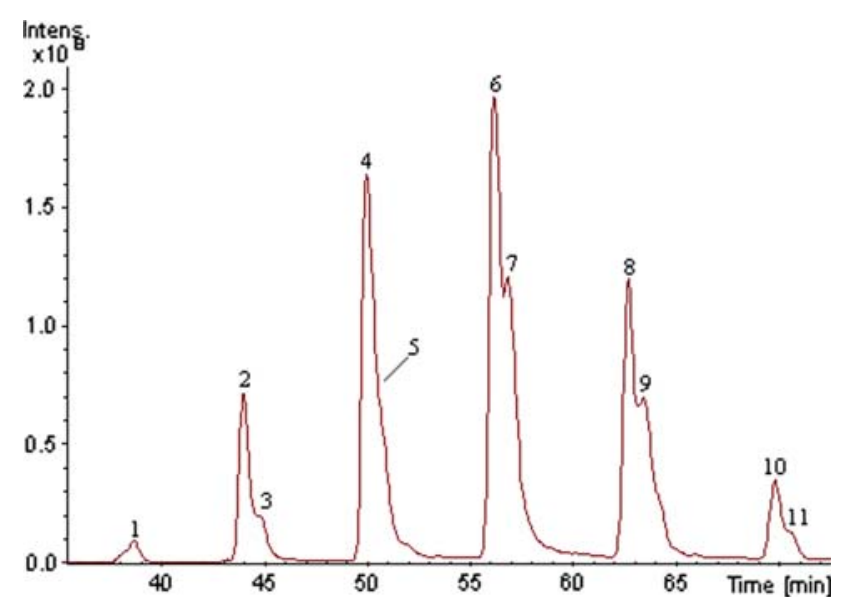

Fig. 3 Reconstructed ion chromatogram of TAG from Annona seed oil achieved by HPLC-APCI-MS

The identification of the molecular species was mainly based on the mass spectral data, the $[\mathrm{M}+\mathrm{H}]^{+}$ion provided molecular weight (MW) information, whereas the information on the FA residues was given by the DAG fragment ions $\left([\mathrm{M}-\mathrm{RCOOH}]^{+}\right.$ion). Positional identification of the FA in the glycerol moiety were possible taking into account some considerations [14]: seed oils normally have PUFA in the $s n-2$ position and the differences between $s n-1$ and $s n-3$ are very small, although less abundant FA tend to appear in the $s n-3$ position; the position of the FA in the glycerol backbone affects the elution order, with 
unsaturated FA in the $s n-2$ position causing the TAG to elute before the TAG with the same FA in the $s n-1$ or $s n-3$ positions; positional isomers can be identified from the relative intensities of the DAG fragment ions, as the least abundant DAG fragment ion is due to the loss of the FA from the $s n-2$ position. This last consideration is quite useful to differentiate between mixed symmetric and mixed asymmetric TAG (ABA and AAB type of TAG) because the $\mathrm{AA} / \mathrm{AB}$ ratio of the $\mathrm{DAG}$ fragment ions is extremely different, being lower than 1 when $\mathrm{B}$ is in the $s n-2$ position.

The suggested FA combinations (Table 2) show that the four main types of TAG were distinguished: AAA, monoacid type (LLL and OOO); AAB, mixed asymmetric type (PLL, OLL, OOL, LLS and OOS); ABA, mixed symmetric type (LLnL, LOL, OLO, OPO and OSO); ABC mixed asymmetric type (OLnL, PLO, OLS, OLA and POS).

Conversion of the Oil into Biodiesel and Its Properties

The amount of FAME obtained by this method was $75.88 \mathrm{~g} / 100 \mathrm{~g}$ of seed oil.

EN 14214 [16] establishes the requirements for biodiesel quality. The parameters determined and calculated for biodiesel quality are shown in Table 3.

The cetane number is related to the ignition of the fuel and a low cetane number indicates that the combustion is not complete. Consequently, part of the fuel remains in the combustion chamber and it will produce more energy than needed when burned, wearing out the engine. As the equations used to predict cetane number are not appropriate to biodiesel, some correlations were developed for methyl esters [19]. A fuel with high "apparent cetane number" (no. 2 diesel fuel has a cetane number of 46) is better for the cold start of the engine, allows a quick warming of the engine and reduces noise and gas emissions to the atmosphere [33]. Biodiesel produced from Annona seed oil has a calculated "apparent cetane number" of 53 (EN 14214 [16] establishes a minimum value of 51).

The iodine value evaluates the number of double bonds, quantifying the unsaturation degree of the fuel, indicating its tendency to oxidation. The iodine number of the biodiesel produced was below the EN 14214 [16] upper limit.

The acidity value determined was also below the EN 14214 [16] upper limit, indicating a low quantity of FFA in the biodiesel produced.

Table 3 Properties of the biodiesel produced

\begin{tabular}{lll}
\hline & Biodiesel & EN 14214 limits \\
\hline Density, $15{ }^{\circ} \mathrm{C}\left(\mathrm{g} / \mathrm{cm}^{3}\right)$ & 0.871 & $0.860-0.900$ \\
Viscosity, $40{ }^{\circ} \mathrm{C}(\mathrm{cSt})$ & 4.4 & $3.5-5.0$ \\
Acid value $(\mathrm{mg} \mathrm{KOH} / \mathrm{g})$ & 0.3 & $<0.5$ \\
Iodine number & $99^{\mathrm{a}}$ & $<120$ \\
Oxidation stability, $110{ }^{\circ} \mathrm{C}(\mathrm{h})$ & 1.17 & $>6$ \\
$\mathrm{CFPP}\left({ }^{\circ} \mathrm{C}\right)$ & -5 & \\
Cloud point $\left({ }^{\circ} \mathrm{C}\right)$ & 1 & - \\
"Apparent cetane number" & $53^{\mathrm{a}}$ & $>51$ \\
\hline
\end{tabular}

a Calculated

Table 2 Molecular species identification of the TAG of Annona seed oil

\begin{tabular}{|c|c|c|c|c|c|c|c|c|c|c|}
\hline Peak \# & $\mathrm{RT}(\min )$ & ECN & TAG & {$[\mathrm{M}+\mathrm{H}]^{+}$} & DAG & {$\left[\mathrm{M}-\mathrm{R}_{1} \mathrm{COO}\right]^{+}$} & DAG & {$\left[\mathrm{M}-\mathrm{R}_{2} \mathrm{COO}\right]^{+}$} & DAG & {$\left[\mathrm{M}-\mathrm{R}_{3} \mathrm{COO}\right]^{+}$} \\
\hline 1 & 38.5 & 40 & LLnL & 877.8 & LnL & 597.5 & LL & 599.6 & & \\
\hline 2 & 43.9 & 42 & LLL & 879.8 & LL & 599.6 & & & & \\
\hline 3 & 44.7 & 42 & OLnL & 879.9 & LnL & 597.6 & $\mathrm{OL}$ & 601.6 & OLn & 599.6 \\
\hline 4 & 49.8 & 44 & LOL & 881.9 & $\mathrm{OL}$ & 601.6 & LL & 599.5 & & \\
\hline \multirow[t]{2}{*}{5} & 50.6 & 44 & PLL & 855.9 & LL & 599.6 & & & PL & 575.6 \\
\hline & & & OLL & 881.9 & LL & 599.6 & & & $\mathrm{OL}$ & 601.6 \\
\hline 6 & 56.0 & 46 & OLO & 883.9 & $\mathrm{OL}$ & 601.6 & $\mathrm{OO}$ & 603.6 & & \\
\hline \multirow[t]{3}{*}{7} & 56.8 & 46 & PLO & 857.9 & LO & 601.6 & $\mathrm{PO}$ & 577.6 & PL & 575.6 \\
\hline & & & OOL & 883.9 & $\mathrm{OL}$ & 601.6 & & & $\mathrm{OO}$ & 603.6 \\
\hline & & & LLS & & SL & 603.6 & & & LL & 599.6 \\
\hline 8 & 62.6 & 48 & $\mathrm{OOO}$ & 885.9 & $\mathrm{OO}$ & 603.6 & & & & \\
\hline \multirow[t]{2}{*}{9} & 63.1 & 48 & OPO & 859.8 & $\mathrm{PO}$ & 577.6 & $\mathrm{OO}$ & 603.6 & & \\
\hline & & & OLS & 885.9 & LS & 603.6 & OS & 605.6 & OL & 601.6 \\
\hline \multirow[t]{2}{*}{10} & 69.7 & 50 & OSO & 887.9 & OS & 605.6 & $\mathrm{OO}$ & 603.6 & & \\
\hline & & & OLA & 913.9 & LA & 631.7 & OA & 633.7 & OL & 601.6 \\
\hline \multirow[t]{2}{*}{11} & 70.5 & 50 & POS & 861.9 & OS & 605.6 & PS & 579.6 & $\mathrm{PO}$ & 577.5 \\
\hline & & & OOS & 887.9 & OS & 605.6 & & & $\mathrm{OO}$ & 603.6 \\
\hline
\end{tabular}

$L$ linoleic, $L n$ linolenic, $O$ oleic, $P$ palmitic, $S$ stearic, $A$ arachidic, $E C N$ equivalent carbon number, $R T$ retention time 
The FAME composition of the biodiesel produced is very similar to the FAME composition of the oil (Table 1), thus indicating that the method for biodiesel production does not promote isomerization or hydrogenation. The predominance of unsaturated FAME makes the biodiesel susceptible to oxidation, but it also balances the viscosity of the fuel, allowing an optimal flow throughout the system. Due to the higher content of saturated FAs (when compared to other oils commonly used for the production of biodiesel) it would be expected that FAME derived from A. cherimola oil would have worse low temperature properties. The results show that these properties are in fact similar to those exhibited by biodiesels produced from soybean or rapeseed oils [34].

\section{Conclusions}

Oil extraction procedures demonstrated that percolation at room temperature yields more oil than at solvent boiling temperature ( 25.1 vs. $22.4 \%$ ). Although the energy balance favors room temperature, it must be taken into account that time is also a very important parameter.

The lipid content of $A$. cherimola Mill. seeds is suitable for making this a promising source of biodiesel as confirmed by the evaluated parameters of the methyl esters. The high degree of unsaturation (all TAG include oleic and/or linoleic acids and FAME analysis confirmed the predominance of these FA) makes the biodiesel produced from this oil susceptible to oxidation, but it also improves (reduces) its viscosity. The low oxidation stability can be overcome by introducing additives into the final product.

Biodiesel production can be a contribution to avoid waste disposal. However, this is a seasonable crop and it must be accompanied by other sources of biodiesel, such as waste cooking oil, another residue with a high economical value.

Acknowledgments The authors are grateful to AGRIPÉROLA for kindly providing Annona seeds, to M. M. Jogo and M. A. Caldeira for performing viscosity, cloud point and CFPP measurements and to A. C. Oliveira and P. Passarinho for aiding on Rancimat ${ }^{\circledR}$ tests. P.C. Branco would like to thank Fundação para a Ciência e a Tecnologia for a Ph.D. grant (SFRH/BD/32334/2006). This work made use of equipments from MS National Network (REDE/1508/REM/2005) and NMR National Network (REDE/1517/RMN/2005).

\section{References}

1. El-Adawy TA, Taha KM (2001) Characteristics and composition of watermelon, pumpkin, and paprika seed oils and flours. J Agric Food Chem 49:1253-1259

2. Ikwuagwu OE, Ononogbu IC, Njoku OU (2000) Production of biodiesel using rubber [Hevea brasiliensis (Kunth. Muell.)] seed oil. Ind Crops Prod 12:57-62
3. Usta N (2005) Use of tobacco seed oil methyl ester in a turbocharged indirect injection diesel engine. Biomass Bioenerg 28:77-86

4. Usta N (2005) An experimental study on performance and exhaust emissions of a diesel engine fuelled with tobacco seed oil methyl ester. Energy Convers Manage 46:2373-2386

5. Kalayasiri P, Jeyashoke N, Krisnangkura K (1996) Survey of seed oil for use as diesel fuels. J Am Oil Chem Soc 73:471-474

6. Andrikopoulos NK, Chiou A, Mylona A (2004) Triacylglycerol species of less common edible vegetable oils. Food Rev Int 20:389-405

7. dos Santos ICF, de Carvalho SHV, Solleti JI, Ferreira de La Salles W, Teixeira da Silva de La Salles K, Meneghetti SMP (2008) Studies of Terminalia catappa L. oil: characterization and biodiesel production. Bioresour Technol 99:6545-6549

8. Ng S (2000) Quantitative analysis of partial acylglycerols and free fatty acids in palm oil by ${ }^{13} \mathrm{C}$ nuclear magnetic resonance spectroscopy. J Am Oil Chem Soc 77:749-755

9. Van Gerpen J, Knothe G (2005) Biodiesel production. In: Knothe G, Van Gerpen J, Krahl J (eds) The biodiesel handbook. AOCS Press, Champaign, pp 26-61

10. ISO 660 (1996) Animal and vegetable fats and oils-determination of acid value and acidity

11. EN 14112 (2003) Fat and oil derivatives - fatty acid methyl esters (FAME) - determination of oxidation stability (accelerated oxidation test)

12. EEC/2568/91 (1991) On the characteristics of olive oil and oliveresidue oil and on the relevant methods of analysis. Off $\mathbf{J}$ Eur Commun L248:1-83

13. EEC/1429/92 (1992) Amending regulation EEC/2568/91. Off J Eur Commun L150:17-20

14. Castilho PC, Costa MC, Rodrigues A, Branco PC, Costa M (2004) Characterization of triacylglycerols in Madeira laurel oil by HPLC-atmospheric pressure chemical ionization-MS. J Am Oil Chem Soc 81:913-919

15. van den Berg JDJ, Vermist ND, Carlyle L, Holčapek M, Boon JJ (2004) Effects of traditional processing methods of linseed oil on the composition of its triacylglycerols. J Sep Sci Soc 27:181-199

16. UNE-EN 14214 (2003) Automotive fuels. Fatty acid methyl esters (FAME) for diesel engines. Requirements and test methods

17. EN ISO 3104 (1994) Petroleum products-transparent and opaque liquids - determination of kinetic viscosity and determination of dynamic viscosity

18. EN 116 (1997) Diesel and domestic heating fuels—determination of cold filter plugging point

19. ASTM D 2500 (2000) Standard test method for cloud point of petroleum products

20. Krisnangkura K (1986) A simple method for estimation of cetane index of vegetable oil methyl esters. J Am Oil Chem Soc 63:552553

21. Ramos MJ, Fernández CM, Casas A, Rodríguez L, Pérez A (2009) Influence of fatty acid composition of raw materials on biodiesel properties. Bioresour Technol 100:261-268

22. Kulkarni MG, Dalai AK (2006) Waste cooking oils-an economical source for biodiesel: a review. Ind Eng Chem Res 45:2901-2913

23. Canakci M, Van Gerpen J (2001) Biodiesel production from oils and fats with high free fatty acids. Trans ASAE 44:1429-1436

24. van de Voort FR, Sedman J, Russin T, (2001) Lipid analysis by vibrational spectroscopy. Eur J Lipid Sci Technol 103(Dossier):815-825

25. Guillén MD, Cabo N (1997) Infrared spectroscopy in the study of edible oils and fats. J Sci Food Agric 75:1-11

26. Guillén MD, Cabo N (2000) Some of the most significant changes in the Fourier transform infrared spectra of edible oils under oxidative conditions. J Sci Food Agric 80:2028-2036 
27. Georgiev A, Karamancheva I, Topalova L (2008) Determination of oxidation products in transformer oils using FT-IR spectroscopy. J Mol Struct 872:18-23

28. Hamed SF, Allam MA (2006) Application of FTIR spectroscopy in the determination of antioxidant efficiency in sunflower oil. J Appl Sci Res 2:27-33

29. Le Dréau Y, Dupuy N, Gaydou V, Joachim J, Kister J (2009) Study of jojoba oil aging by FTIR. Anal Chim Acta 642:163-170

30. Balat M, Balat $H$ (2008) A critical review of bio-diesel as a vehicular fuel. Energ Convers Manage 49:2727-2741

31. Ma F, Hanna MA (1999) Biodiesel production: a review. Bioresour Technol 70:1-15
32. Andrikopoulos NK (2002) Triglyceride species compositions of common edible vegetable oils and methods used for their identification and quantification. Food Rev Int 18:71-102

33. Encinar JM, González JF, Rodriguez JJ, Tejedor A (2002) Biodiesel fuels from vegetable oils: transesterification of Cynara cardunculus L. oils with ethanol. Energy Fuels 16:443-450

34. Krishna CR, Thomassen K, Brown C, Butcher TA, Anjom M, Mahajan D (2007) Cold flow behavior of biodiesels derived from biomass sources. Ind Eng Chem Res 46:8846-8851 